\title{
Contemporary Digital Home Work
}

\author{
Old Challenges, Different Solutions?
}

\author{
Janine Berg
}

Digital labour platforms provide the technical infrastructure for businesses and individuals to access a large number of potential workers across the globe - "the crowd" - who can perform a myriad of tasks in a relatively short time, with the business having no further obligation to those workers. ${ }^{1}$ These "crowd-working" platforms mediate the work between clients and workers. They offer workers a centralized location for identifying tasks from many different requesters, a method for submitting work products, and the technical and financial infrastructure to receive payment for work completed.

Crowd work resembles many long-standing work arrangements, but with a digital tool serving as intermediary. The strategies of crowd work that centre on breaking down tasks into small units assignable to unskilled workers are "a throwback to the de-skilled industrial processes associated with Taylor, but without the loyalty and job security". ${ }^{2}$ Yet the payment structure by task rather than time and the home-based location of the workers means that crowd work can be considered a form of contemporary digital home work. Indeed, it is subject to many of the concerns of labour exploitation common to industrial home work. Currently, workers on crowd-working platforms are not covered by labour protection, and workers have little control over when they will have work or their working conditions. They also have limited options for recourse in cases of unfair treatment.

This paper draws on findings from original surveys of micro-task workers of five leading micro-task platforms, covering 3,60o workers from 75 countries, conducted by the International Labour Organization (ILO) in 2015 and 2017. ${ }^{3}$

1 The views expressed in this paper are my own and do not necessarily reflect the views of the ILO.

2 Miriam A. Cherry, "Beyond Misclassification: The Digital Transformation of Work", Comparative Labor Law and Policy Journal, 37 (2016), pp. 578.

3 For more details on the survey and its results, see Janine Berg, "Income security in the ondemand economy: Findings and policy lessons from a survey of crowd workers", Comparative Labor Law and Policy Journal, 37 (2016), pp. 543-76, and Janine Berg et al., Digital Labour Platforms and the Future of Work: Towards Decent Work in the Online World (Geneva, 2018).

(C) JANINE BERG, 2022 | DOI:10.1163/9789004499614_019

This is an open access chapter distributed under the terms of the CC BY-NC-ND 4.o license. 
The findings provide information on the socio-demographic characteristics of the workers, their reasons for entering crowd work, their financial situation, their working conditions, as well as the different work experiences of women and men crowd workers. Based on the survey, I draw some parallels between the experiences of crowd workers and that of industrial home workers, but also distinguish between the two when discussing possible regulatory options.

Amazon launched its first crowd-sourcing platform in the mid-20oos internally when it realized that its computer programmes could not correctly classify the products in its growing online catalogues. Originally conceived as something for Amazon employees to do in their "spare time", the company soon realized that it could outsource the tasks to a crowd of workers across the globe, ${ }^{4}$ as well as provide a platform for other companies to post tasks. Ironically, it was the failure of artificial intelligence that spurred the need for human input, and which continues to fuel demand for an array of activities needed for the smooth functioning of the internet and the wider digital economy.

On web-based crowd-working platforms, work is posted online and a worker located in any part of the world, so long as she has a reliable internet connection, can access the work, perform it, submit it and receive payment. ${ }^{5}$ There are a range of crowd-working platforms, from higher skilled, macro-task platforms where workers offer their services as graphic designers, computer programmers, statisticians, translators and so on, to micro-task platforms which typically involve clerical tasks that can be completed quickly and require less specialized skills. Common tasks on micro-task platforms include copywriting and other forms of content creation for websites; visiting websites or downloading apps to increase traffic and for search optimization ("content access"); product categorization; verifying and validating data (e.g., verifying if a Twitter account is for a real person); content moderation (removal of pornography or violent images before they are uploaded on social media accounts); writing (fake) reviews; text or audio transcription; and filling out surveys, for either market research or academic purposes. ${ }^{6}$

4 Lilly Irani, "Difference and Dependence among Digital Workers: The Case of Amazon Mechanical Turk", South Atlantic Quarterly, 114 (2015), pp. 225-34.

5 The study does not consider workers on local, app-based digital labour platforms, such as Uber, Deliveroo or TaskRabbit, as this work is not performed in the home.

6 Berg et al., Digital Labour Platforms and the Future of Work. 
Well-known macro-task platforms include Upwork, Freelancer.com and Jovoto, though there are scores more operating in different languages and markets, and specializing in particular fields. Most of these platforms are designed so that workers set up individual profiles, indicate their expertise and their rate, with the final price for their work set via a bargaining process with the clients. Clients can pay per project or on an hourly basis; if hourly, the platform facilitates monitoring of the work through special software that counts keystrokes and takes random screenshots using the worker's webcam. The platform charges a fee, typically ranging from 10 to 25 per cent depending on the platform; this is charged to either the worker or the client. ${ }^{7}$

Micro-task platforms are more one-sided. Clients post tasks on the platform, either directly using an application programming interface (API), or through the platform company which breaks up the work into micro-tasks and then uploads it. Workers see the tasks posted and as long as they have the right qualifications (usually a minimum threshold for their rating and experience, though they may also be required to pass unpaid qualification tests), they can access the job, complete it and submit it. Prices are set by the client or platform, and there is no negotiation. Fees are charged to the client and not the worker.

Like traditional home-based workers, crowd workers fall in a "grey intermediate zone" between independence and dependency. ${ }^{8}$ While macro-task workers exercise much greater independence than micro-task workers, and are more akin to self-employed home-based workers, they are still subject to control and dependency on the platforms and an unequal bargaining position with the client. Like self-employed home-based workers, they have limited access to capital, limited control in commercial transactions, and are acutely aware of the global competition from workers with similar skill-sets. However, the monitoring of their work through the platform's software suggests a degree of control that is greater than amongst self-employed home-based workers in traditional industries.

Micro-task workers have many similarities with subcontracted home-based workers, also commonly referred to as industrial outworkers or home workers. Like their sisters in traditional home work, they absorb many of the costs and risks of production, including paying for their computers, internet connection and electricity, and are also subject to control by the client and the platform,

7 Mariya Aleksynska et al., Work on Digital Labour Platforms in Ukraine: Issues and Policy Perspectives (Geneva, 2018).

8 Martha Alter Chen, Informal Economy Monitoring Study Sector Report: Home-Based Workers (Cambridge, MA, 2014). 
possibly to a greater extent than in traditional home work. They are paid by piece (or 'task'), and they bear the risk of fluctuations in demand as well as other inefficiencies in the organization of work.

\section{Exercising Control in Crowd Work: Management through} Algorithm

A critical difference between traditional and digital home work is its management. While both forms of home work rely on an intermediary who offers the tasks, controls quality and ensures payment, on digital platforms most of these functions are automated. ${ }^{9}$ The process of posting tasks, evaluating results and paying workers can be automated through algorithmic programmes. ${ }^{10}$

Following the worker's selection of task(s) on the platform, the work is in many instances "supervised" by an algorithm that controls the work process, the worker's submission and the worker's payment. Relegating the supervision to an algorithm may result in instances of unfair treatment. For example, when three workers perform a particular task and if the result of one of the workers is different from that of the other two, then the algorithm may be set up to automatically reject the work of the one response that is different, even if it is correct. Thus, having an algorithm review the work runs the risk of rejecting work that has been completed well. Also, workers often do not know why the work was rejected, either because they do not receive an answer or because the answer is unclear. As one large-scale requester on Amazon Mechanical Turk explained, "You cannot spend time exchanging e-mail. The time you spend looking at the e-mail costs more than what you paid them. This has to function on autopilot as an algorithmic system ... and integrated with your business processes" (personal communication with L. Irani). ${ }^{11}$

9 Berg et al., Digital Labour Platforms and the Future of Work; Min Kyung Lee et al., "Working with Machines: The Impact of Algorithmic and Data-Driven Management on Human Workers", CHI 2015: Proceedings of the 33rd Annual ACM Conference on Human Factors in Computing Systems (Seoul, 2015).

10 Management through algorithms concerns not just the web-based micro-task crowdsourcing platforms studied in this report, but also "location-based" digital labour platforms that direct workers to deliver local services, such as Uber or Deliveroo. See Lee et al., Working with Machines, and Alex Rosenblat and Luke Stark, "Algorithmic Labor and Information Asymmetries: A Case Study of Uber's Drivers", International Journal of Communication, 10 (2016), pp. 3758-84, for a discussion of the algorithmic management used by Uber.

11 Irani, "Difference and Dependence among Digital Workers", p. 228. 
This approach is unfair to the worker for the following reasons. First, because the worker is often not given feedback for the rejection, and thus misses the opportunity to learn from his or her mistake and improve future performance. Second, it is possible that the work is actually still useful to the requester, in which case non-payment constitutes wage theft. In addition, rejections can affect the workers' ability to get new tasks or even lead to workers being deactivated (in essence, fired) from the platform automatically when a certain threshold of rejections is reached. For example, on АM T a standard criterion used to attribute work on the platform is an approval rating of at least 95 per cent. On the platform, Microworkers, workers whose approval rating ("temporary success rate") falls below 75 per cent are prevented from performing jobs for the next thirty days. On the platform, CrowdFlower, "Individual customers/ clients have the power to accept or reject any submission by a CrowdFlower worker, as well as to 'flag' the account of workers in such a way as to prevent workers from receiving future work".12 More troubling is the fact that there are no mechanisms through which the worker can contest the decision.

\section{Insufficient Work, Low Earnings and Inefficiencies Borne by the} Worker $^{13}$

Like traditional home work, micro-task workers work when work is available, and are paid by piece for the work they perform. The ILO survey included a detailed question on working time, which revealed that there was a considerable amount of down-time or unpaid working time associated with microtask work. Indeed, the survey found that for every hour of paid work, workers averaged eighteen minutes of unpaid work. This was time spent looking for the tasks, reading reviews about the requester to ensure they are fair and honest, and taking unpaid qualification tests.

An overwhelming majority (88 per cent) of the micro-task workers surveyed by the ILO responded that they would like to do more work. On average, these individuals wished to do 11.6 more hours of crowd work per week. The willingness to do more crowd work was similar among both men (86 per cent) and women (9o per cent). Across regions, it was especially high in Africa (98 per

12 http://faircrowd.work/platform/crowdflower/, accessed 5 January 2018.

13 This section draws from Berg et al., Digital Labour Platforms and the Future of Work. I would like to thank my colleagues, Uma Rani and Marianne Furrer, as well as Six Silberman and Ellie Harmon, for their collaboration on the report. 


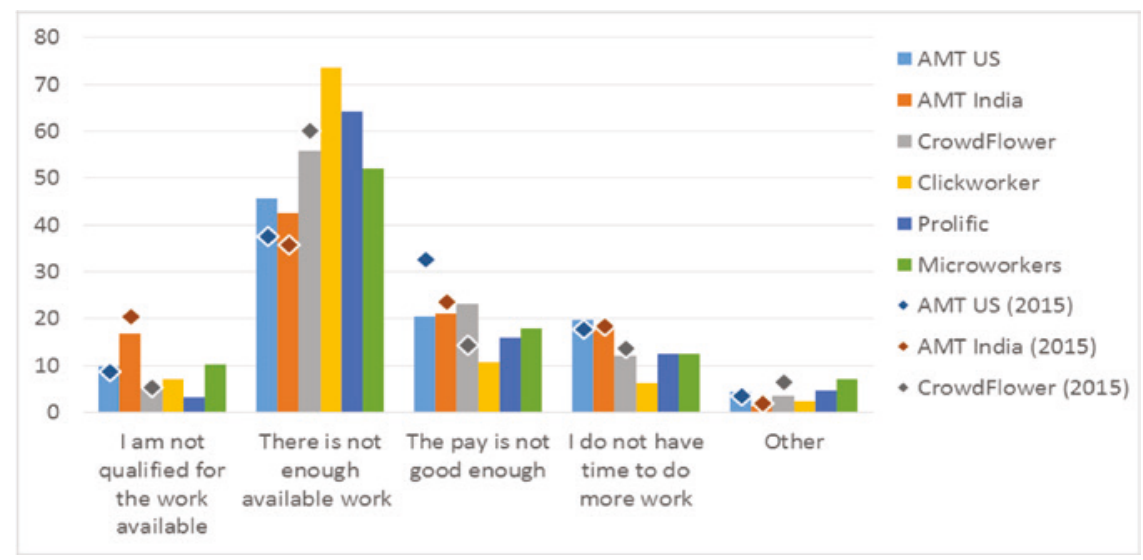

GRAPH 16.1 Reasons for not doing more crowd work currently (percentage by category)

cent), Central East Europe ( 96 per cent) and Asia (91 per cent); 8o per cent of North Americans expressed a desire for more work.

Sixty per cent of workers on all platforms except American workers on AMT (46 per cent) indicated that they would like to do more work that is not crowd work. When asked why they were not currently doing more crowd work, $5^{8}$ per cent replied that the availability of tasks was insufficient and an additional 17 per cent did not find enough well-paid tasks (Graph 16.1). A higher proportion of workers in Europe (68 per cent) mentioned that they did not find enough work as compared to workers in Asia (48 per cent). As some workers explained:

The toughest part of turking ${ }^{14}$ for a living is actually finding the jobs; for every hour I spend working I most likely spend two hours monitoring the various scripts I have running to see what jobs show up. - AM T worker

I would like to change how hard it is to find the jobs to work on. I often have some time to do a task, but cannot find anything to work on. AMT worker

You cannot expect people to spend time on "test questions" and then not give them paid work when they have finished - yet this happens every day, the forums are full of complaints. If there is no work left on a job, the job should be removed from the task list. This does not happen. CrowdFlower worker

"Turking" is slang for working on the Amazon Mechanical Turk platform. 
Indeed, the pressure to remain online to find work appears to erode the flexibility that is so coveted in the job. As one AMT worker stated in response to what they would change about crowd work if they could, "I would want to know when tasks are up so I can plan my day".

Ironically, crowd work appears to provide less employment stability than traditional home-based work. Home-based workers employed as weavers, embroiderers or beedi rollers are usually provided with sufficient work to last several days. In crowd work, the search for work is continuous. This unpaid and excessive search time exacerbates underemployment and feelings of insecurity, besides affecting the earnings of the workers.

The ILO survey found that on average, in 2017, a worker earned US $\$ 4.5$ o per hour if only paid work was considered, and if total paid and unpaid hours were considered, then the average earning reduced to $\$ 3.4$ o per hour. If we take only time spent on paid work, then, depending upon the platform and country of the worker, workers earned between $\$ 2.70$ (CrowdFlower) and \$8.60 (АMT US) per hour. The average earnings reduced to between $\$ 2.00$ (CrowdFlower) and \$6.6o (AMT US) when accounting for unpaid work.

A substantial proportion of the workers earn below their local minimum wage. For instance, in 2017, about 48 per cent of American workers on the AMT platform earned less than the federal minimum wage of $\$ 7.25$ when only paid work was considered, and this proportion increased to 64 per cent when unpaid work was taken into account. A recent data-driven study which involved a plug-in that tracked worker log data of approximately 2,500 workers over two years on АMT, found that taking into account unpaid work, the median hourly wage was around $\$ 2$ per hour and the mean wages of workers amounted to $\$ 3.13$ per hour. The study further found that only 4 per cent of workers earned above $\$ 7.25$ per hour, raising concerns about below minimum wage earnings. ${ }^{15}$ The German-based platform Clickworker advertises an average earning of $\$ 9$ per hour. ${ }^{16}$ This roughly corresponded to the German minimum wage of $€ 8.84$ per hour as of 1 January 2017. However, the average wage on Clickworker was $\$ 4.6$ per hour of paid work, and among the survey respondents, only 11 per cent of workers on Clickworker reported earning $\$ 9$ or more per hour of paid work; this reduced to 7 per cent if both paid and unpaid work were taken into account.

\footnotetext{
15 Kotaro Hara et al., "A data-driven analysis of workers' earning on AMT", CHI 2018:Proceedings of the annual Conference on Human Factors in Computing Systems (Montreal, 2018).

16 "Depending on qualifications, speed, practice and concentration you can earn well over \$10.0o per hour. On average, we expect that a Clickworker earns \$9.oo per hour", https:// www.clickworker.com/clickworker-job/, last accessed 18 January 2018.
} 
Graph 16.2 presents the distribution of hourly paid and unpaid work across the five platforms. The distribution of hourly paid work is skewed towards the left for all the platforms, and becomes even more skewed when unpaid work is taken into consideration. As a result, a high proportion of workers are remunerated below the average wage per hour: 59 per cent of American workers on AMT; 61 per cent on Prolific; and around 70 per cent of workers on CrowdFlower, Clickworker and Microworkers and Indian workers on AMT. The "typical" (median) worker earns much less than the platform average, namely $\$ 2.16$ across all platforms, and as little as $\$ 1.01$ per hour for paid and unpaid work on Microworkers. This means that half the workers earn less than $\$ 2.16$ per hour of the total time (of paid and unpaid work) that they invest into crowd work.

The organization of crowd work at present requires very little investment by the platforms. With the exception of the set-up and maintenance of the server there are no fixed costs; labour costs are tied to sales and not covered directly by the platform, and are therefore entirely variable. According to Silberman and Irani, ${ }^{17}$ only eight workers are employed by Amazon to maintain and administer the Amazon Mechanical Turk platform. Yet, because the workers are paid by piece, and bear the burden or cost of tasks that are not clearly explained or of downtime from searching for work, there is no incentive for the platforms to organize the work in a manner that would be more efficient for the workers.

Who Are Crowd Workers? Why Do They Perform Crowd Work?

Crowd workers are well-educated and digitally skilled, and live in households with computers and internet connection. Many combine crowd work with other paid employment activities, while others perform crowd work because of a need or preference to work from home. Although their work is invisible, unlike traditional home workers, they are not, generally, from marginalized communities, nor do they represent the poorest of the poor. Nevertheless their involvement in the work, given the conditions described in the previous section, points to an extension of the restructuring that led to an increase in home work in manufacturing industries in industrialized countries in the $198 \mathrm{os},{ }^{18}$

17 M. Six Silberman and Lilly Irani, "Operating an employer reputation system: Lessons from Turkopticon, 2008-2015”, Comparative Labor Law and Policy Journal, 37 (2016), pp. 505-41.

18 Mireia Baylina and Michaela Schier, "Home work in Germany and Spain: Industrial restructuring and the meaning of home work for women", Geo Journal, $5^{6}$ (2002), pp. $295^{-304 .}$ 

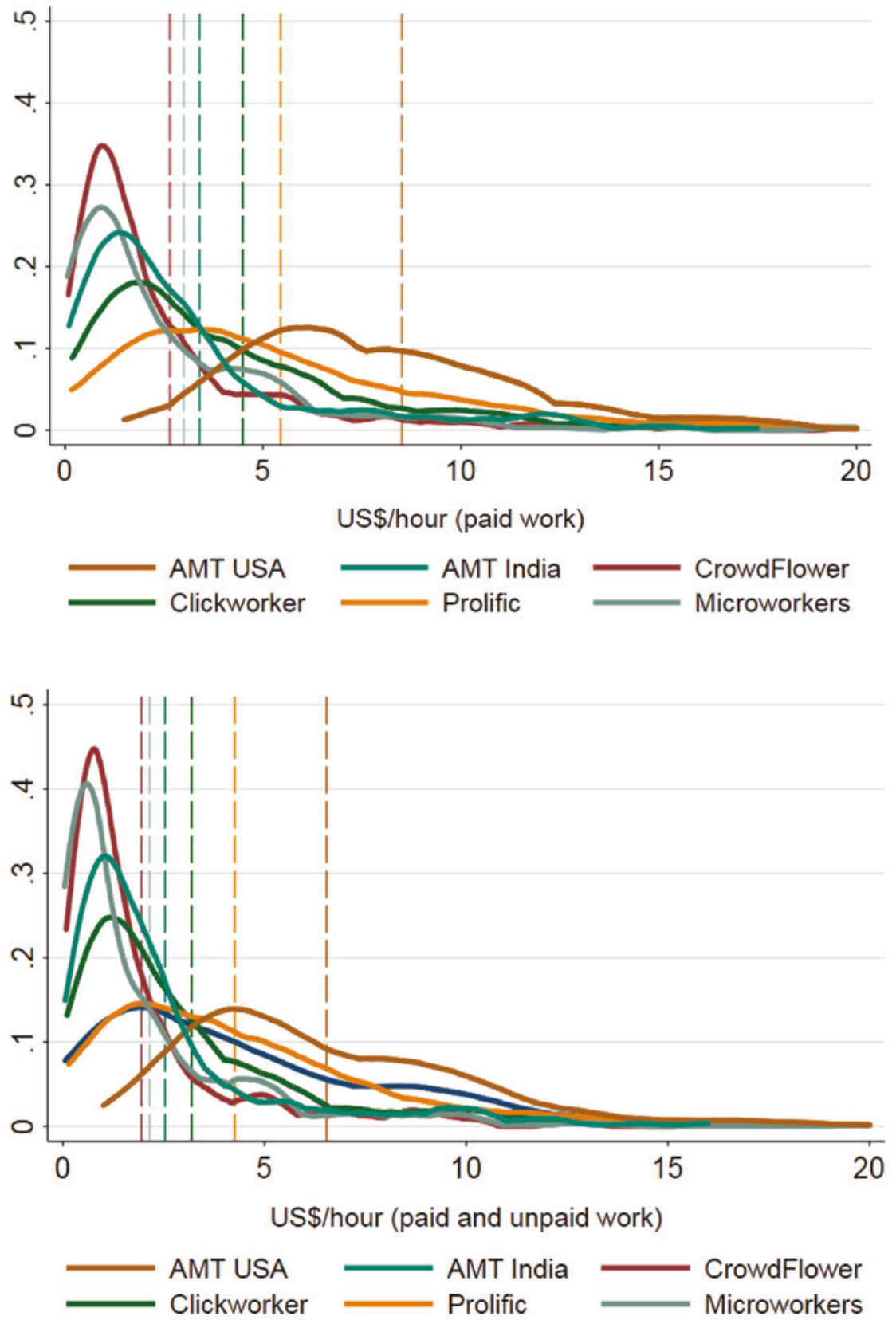

GRAPH 16.2 Distribution of hourly paid and unpaid work among workers by platform, 2017 (in US\$) 
as well as the outsourcing of business process activities in the 199os to backoffices in developing countries. It therefore appears that with crowd work we are seeing an extension of work restructuring that affects higher skilled workers in the service sector, made possible by the growth of digital technologies.

One of the important differences between crowd workers and traditional home workers is the gender composition, which, though not uniform across countries, reveals a greater predominance of men, especially in developing countries (see Graph 16.3). In the United States, where the work is considered to be low-paid, there was near gender balance in 2015 , and a slight lowering in 2017. In developing countries, however, men outnumbered women on the micro-task platforms surveyed by the ILO in 2017 by a ratio of five to one. While still a low-paid job, with earnings of around $\$ 3$ per hour, the wage compares more favourably with local earnings. But perhaps more important than the relative wage levels, many of the workers had an educational background in the field of science and technology that is otherwise dominated by men, which possibly contributed to their interest in engaging in micro-task crowd work.

The average age of crowd workers was 33.2 years in 2017 , slightly lower than the 34.7 years in 2015 (Graph 16.4), though the range differed across platforms. Workers on the platform, Prolific, were on average younger, at 30.3 years, as compared to American workers performing tasks on AMT, at 35.8 years, in 2017. Most crowd workers were aged 25 to 40 years; 10 per cent of them were above the age of 50 years.

Crowd workers are well educated, with more than 8 o per cent having done post-secondary school studies. About one-third of the workers have a technical

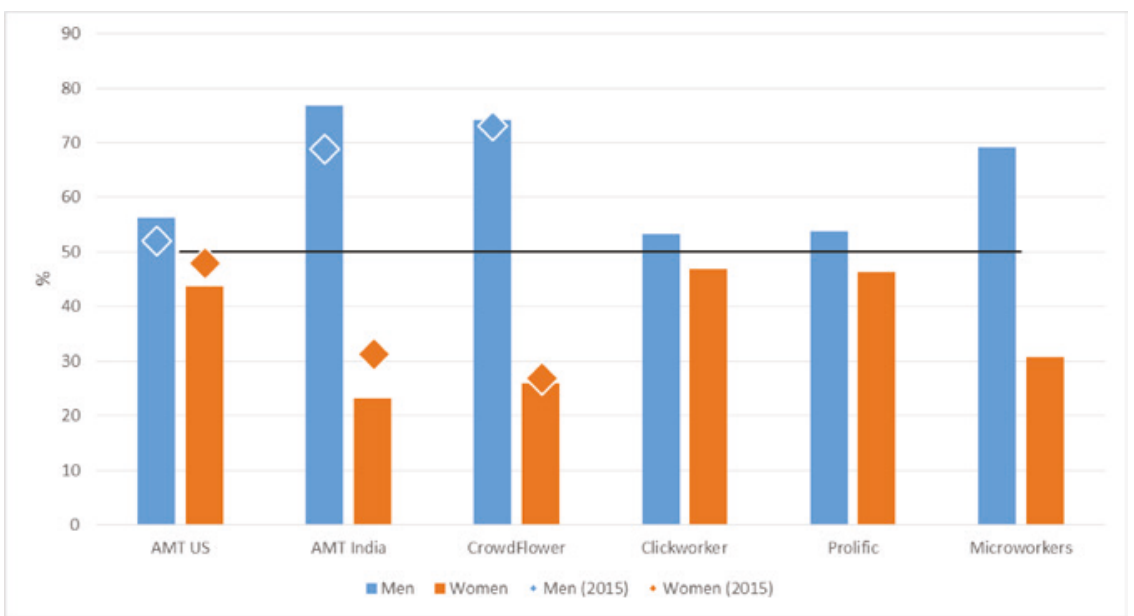

GRAPH 16.3 Distribution of crowd workers, by platform and gender 


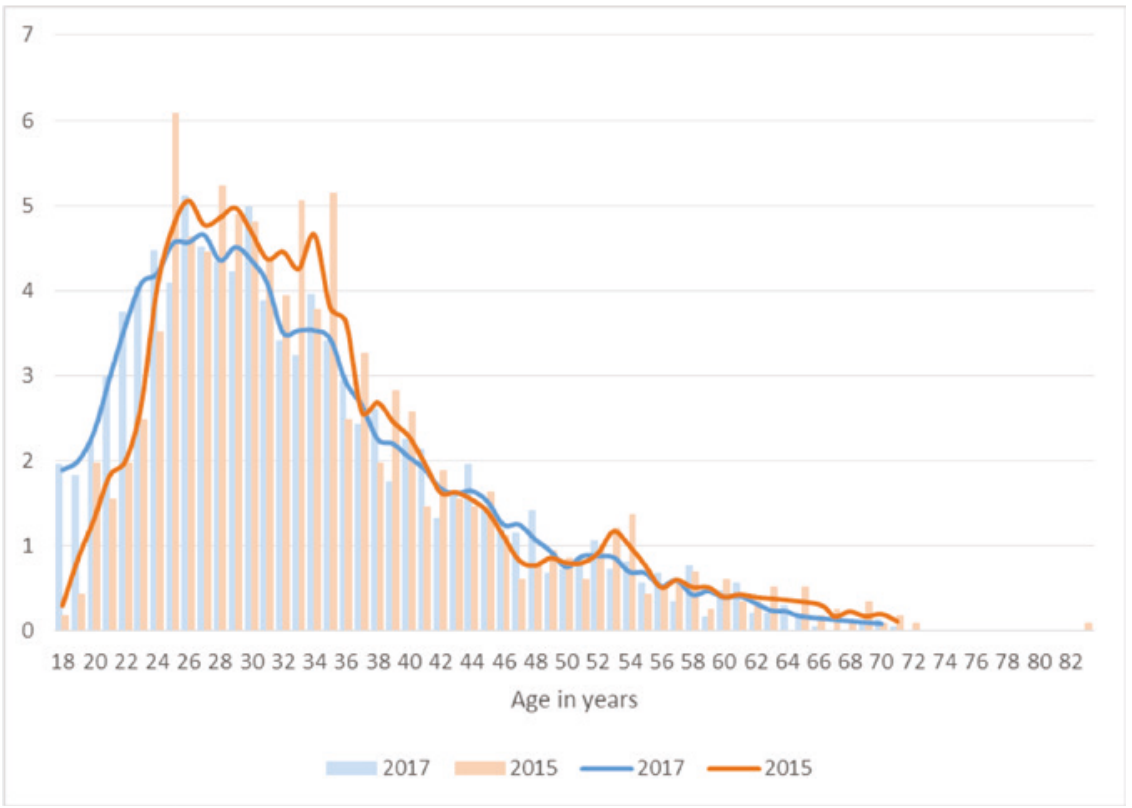

GRAPH 16.4 Age distribution of crowd workers, all platforms

certificate or have completed some university courses, 37 per cent have a college (Bachelor's) degree, and 20 per cent have a postgraduate (Master's) degree (Graph 16.5). These proportions are similar for both the 2015 and 2017 surveys. Education levels are high in Asia with 8 o per cent of the workers having a college degree as compared to Africa, where it is the lowest at 47 per cent. Across platforms, a high proportion of Indian workers on АMT have college degrees (57 per cent) or postgraduate degrees (35 per cent), compared to 48 per cent of Microworkers respondents and 44 per cent of American workers on AMT in 2017. One-fifth of crowd workers are currently pursuing a university degree, ranging from 17 per cent in North America to 40 per cent in Africa.

Crowd workers are almost equally divided between those who are single (48 per cent) and those who are married or co-habiting (47 per cent). Workers in developing countries live in larger households; very few live alone. Among AMT workers, 27 per cent of American workers lived alone as compared to just 1 percent of Indian workers.

For the sample as a whole, about 43 per cent of the respondents had children living in their households in 2017, which was slightly higher than in 2015 (41 per cent); 8o per cent and 86 per cent workers in 2017 and 2015, respectively, reported that these were their own children. Among respondents with children, more than $5^{\circ}$ per cent had children under the age of six years ${ }_{5} 6$ 


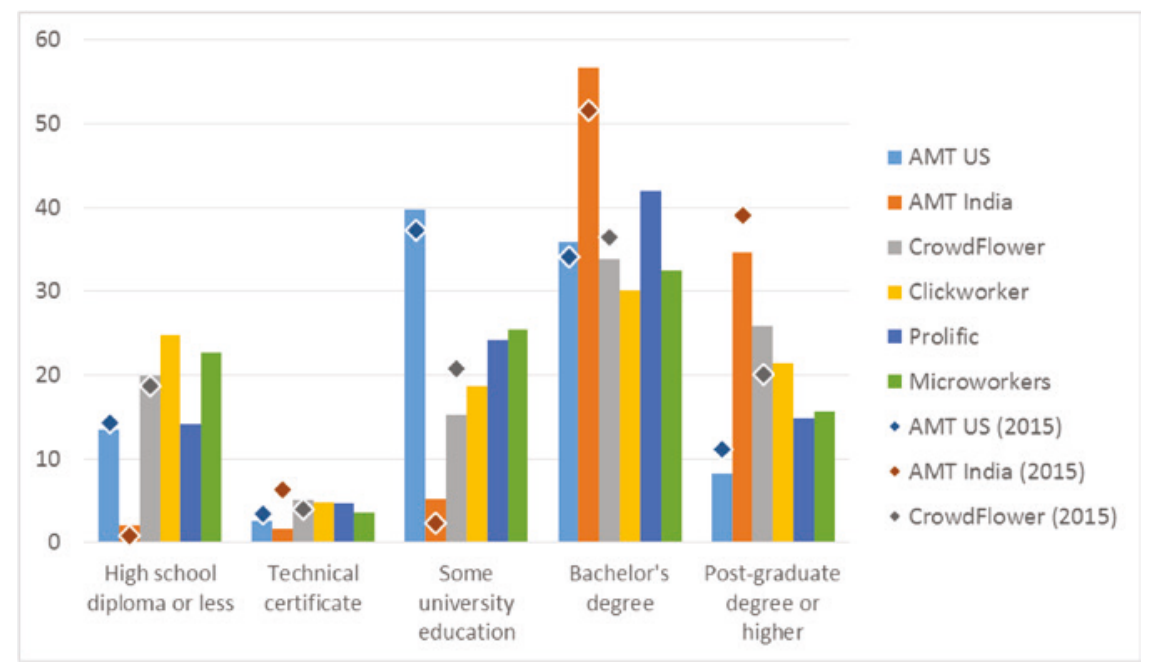

GRAPH 16.5 Educational levels of crowd workers (percentage by category)

per cent in 2017 and 61 per cent in 2015). In 2015, a higher proportion of Indian workers on АMT had children under the age of six (37 per cent) as compared to American AMT workers (16 per cent); these proportions were similar in 2017.

\section{$5 \quad$ Reasons for Crowd-working}

The survey asked workers about their reasons for undertaking crowd work and if they responded with several reasons, they were asked to identify the most important one. In 2017, for about 22 per cent of workers the most important reason for performing crowd work was that they "prefer to work from home", and for 32 per cent it was "to complement pay from other jobs". These proportions were 20 per cent and 36 per cent in 2015 (Graph 16.6). There were important differences across platforms; for example, "to complement pay from other jobs" was more important for workers on Prolific and American workers on АMT (around 44 per cent). These two reasons were also the most important in all the regions. In addition, 22 per cent of workers in Latin America (with strong representation from Venezuela and Brazil) and 9 per cent of Indian workers on AMT preferred crowd work because the "pay is better than for other jobs available". Respondents on other platforms or regions did not share this view. There were strong differences by gender for those who could "only work from home", with 15 per cent of women workers giving this reason as compared to 5 per cent of men. Across platforms this perception was quite high among Indian female 
workers on АMT (20.7 per cent), compared to Indian male workers on AMT (10 per cent). The other reason cited for undertaking crowd work was that "they enjoyed it" (9.5 per cent), a view shared in particular by Indian workers on AMT (14.7 per cent) and workers on Prolific and Microworkers (10 per cent).

The qualitative information provided by the respondents also brought out the care responsibilities (caring for children, disabled or elderly adults) that many of them had, which restricted them from undertaking work outside their homes.

I am unable to work, because I take care of my ill mother and being a crowd worker gives me the flexibility and means to make some money while I am confined to home. - Respondent on AMT, USA

I can only work from home because I can't leave my Mom who is sick. Respondent on Microworkers, Philippines

I have a sick child [autism and cancer] and he needs all-day care. Respondent on CrowdFlower, Republic of Serbia

I really like that it gives me the freedom to be home with my kids but make a little income when I can. - Respondent on Microworkers, USA

Health problems were also mentioned as one of the reasons why the respondents preferred to work from home or could only work from home. Sixteen per

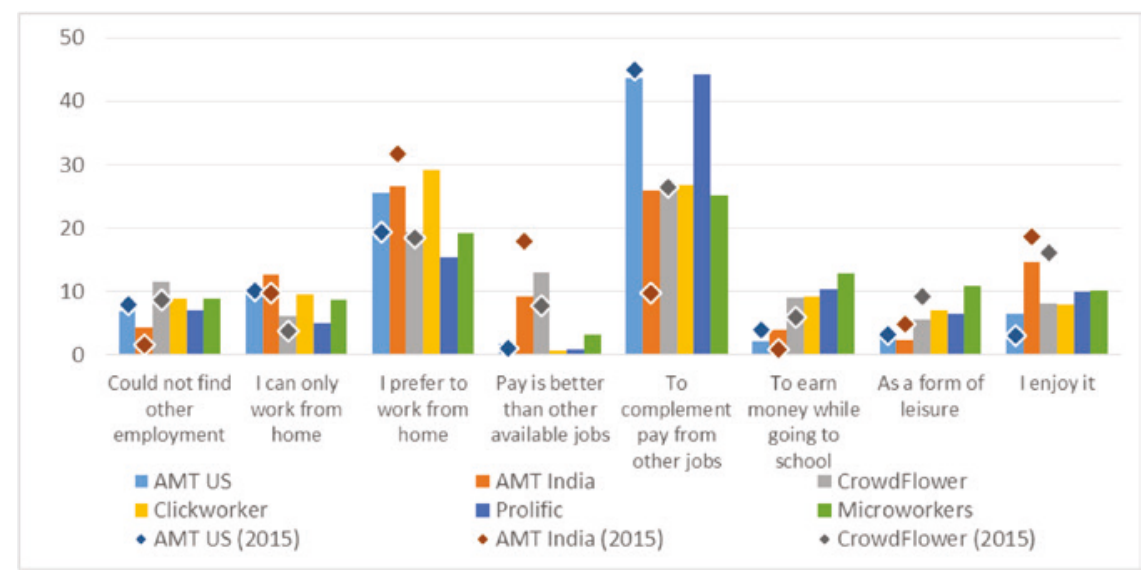

GRAPH 16.6 Most important reason for doing crowd work, by platform (percentage by category) 
cent of respondents described their health as fair; 4 per cent described it as poor or very poor. About 19 per cent of respondents reported current physical or mental health conditions or illnesses lasting or expected to last 12 months or more. For more than half of these individuals (54 per cent), these health problems affect the kind of paid work they can do. For about 18 per cent of them, the health conditions or illnesses affect their ability to carry out day-to-day activities, and crowd work seems to provide an alternative way of continuing to work and earn some income.

\section{A Closer Look at Care Responsibilities among American AMT Workers $^{19}$}

Looking more closely at the samples, there were key differences regarding the structure of households and care responsibilities between male and female crowd workers. Among American AMT workers, 47 per cent of women as compared to 24 per cent men had children at the time of the survey, a huge 23 percentage point gap (see Graph 16.7). American women also lived in larger households; the average household size for female crowd workers was 2.86 compared to 2.39 for male crowd workers. Many more women come to crowd work from care roles, and have care responsibilities while crowd-working.

Male crowd workers have a slightly greater attachment to the offline labour market and are more likely to be working in a technical occupation. While the proportion of the sample working in the "offline" economy is large (59 per cent women and 67 per cent men), men are 9 per cent more likely than women to hold additional jobs besides crowd work (see Graph 16.8). Amongst those not engaged in crowd work, men work more hours in paid work (between 30 to 36 hours per week) and have significantly higher average earnings (typically, between $\$ 400$ to $\$ 700$ per week). While the majority of men with offline jobs work in professional and technical occupations, a larger proportion of women work in support and clerical occupations.

The motivation for entering into crowd work differs by gender. Extra pay is the most important factor influencing the decision to crowd work. While this is also important for a sizeable proportion of women (39 per cent), women are 11 percentage points more likely to report that their most important reason for doing crowd work is because it is difficult for them to work outside

19 This section draws from Abi Adams-Prassl and Janine Berg, When Home Affects Pay: An Analysis of the Gender Pay Gap among Crowdworkers (2017), available at SSRN: www.ssrn.com or www.dx.doi.org last accessed 2 June 2021. 


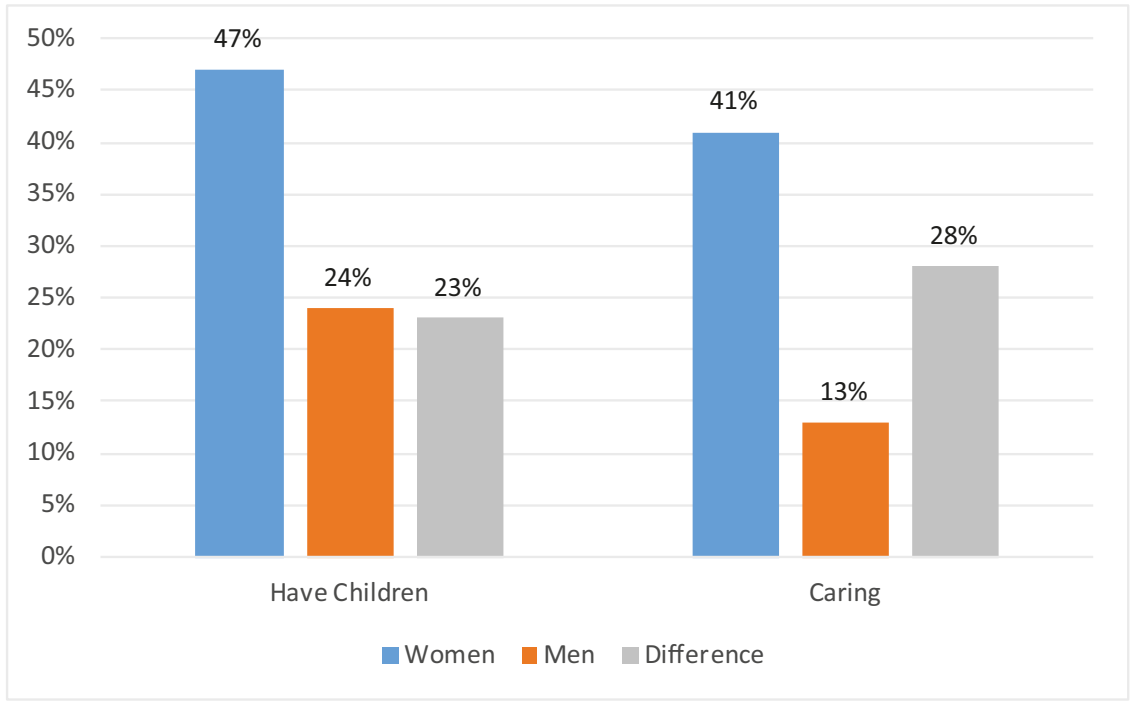

GRAPH 16.7 Gender differences in care responsibilities

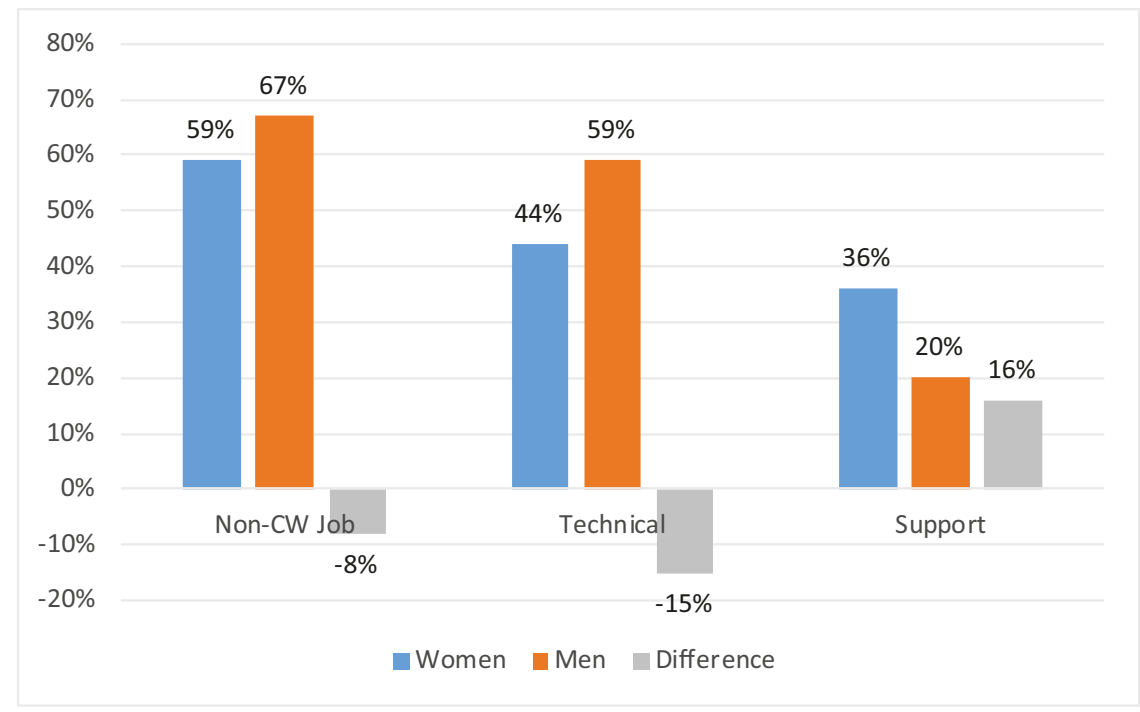

GRAPH 16.8 Gender differences in offline labour market activity

the home(24 per cent for women compared with 35 per cent for men). There was also an important share of the sample (14 per cent overall) that reported health problems which interfere with their ability to complete day-to-day tasks. Among women, 18 per cent reported a health problem that affects the 
kind of paid work they might do; 10 per cent of men reported similar health problems (see Graph 16.9).

Not surprisingly, women are more likely to report juggling crowd work and care duties in the home at the same time. In their qualitative responses to the survey, approximately 11 per cent of women explicitly mentioned that they do domestic work and crowd work simultaneously; only 2 per cent of men mentioned this.

For these women, the reliance on crowd work is analogous to the experience of industrial home workers in traditional industries. They work from home because it is not possible for them to participate in paid employment outside the home, either because of their domestic responsibilities or because of a lack of income-earning opportunities outside the home. Like home workers across the world, they are paid by the piece, experience great uncertainty in whether they will continue to have work and are at the mercy of agents who control the flow of work for their payment.

Yet there are two main differences: the women (and men) performing crowd work are more educated, and have digital literacy skills that allow them to communicate with other crowd workers at online fora. In addition, the technology on which the work is based offers the potential for more effectively regulating the work to ensure compliance with labour protection.

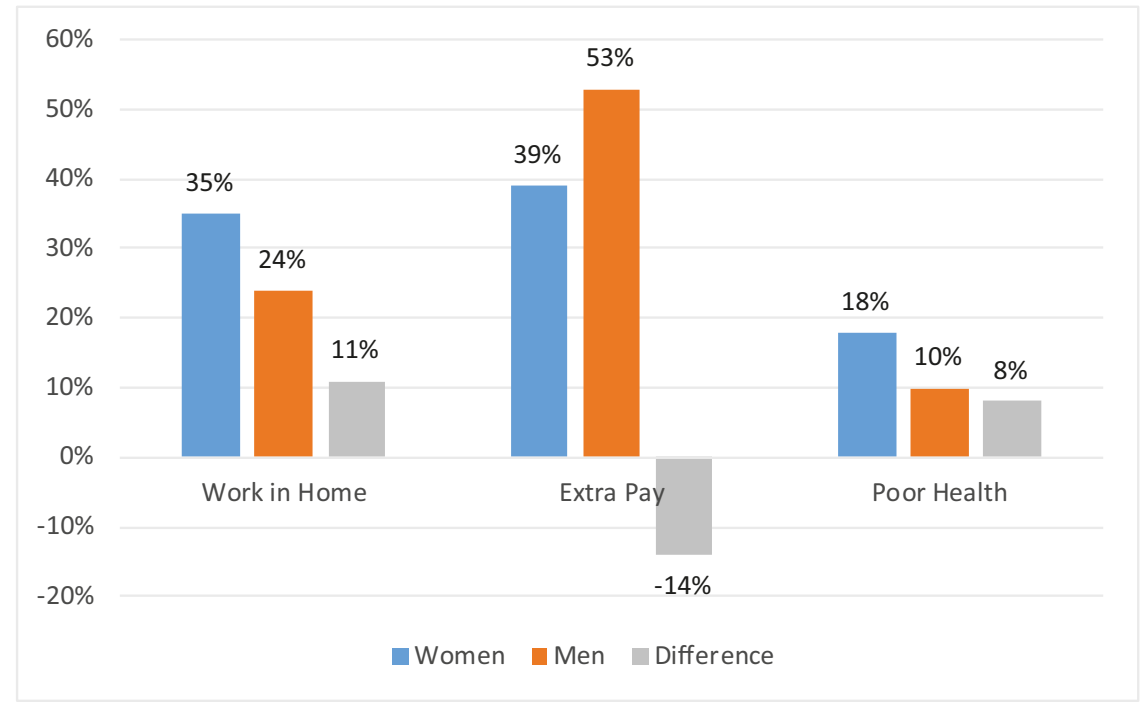

GRAPH 16.9 Gender differences in reasons for crowd-working 


\section{Regulating Crowd Work: Technological Tools for Ensuring Effective} Protection

While home work has always been difficult to regulate because of its invisibility, the situation of crowd work differs in two fundamental aspects: (1) the work is dispersed among workers located throughout the world; and (2) the technology that mediates the platforms offers potential for regulating the working conditions, thus making the invisible visible. In this section, I discuss the implications of these two attributes of crowd work for its possible regulation in the future.

At present, there is no government regulation of crowd work, with the platforms self-governed through unilaterally established "terms of service". Work on digital labour platforms is not unregulated - rather, it is "platformregulated". The platforms decide how information is collected and displayed, how and in what contexts participants are exposed to each other, who can work on the platform and the status they will have, as well as whether or not to intervene and mediate disputes. ${ }^{20}$ Clients and platforms use the data they gather on the work that is done to refine learning algorithms used by them for governance and management purposes. Workers do not have access to the data that they are generating through their work and activity on the platform, nor do they have information about the algorithms used to govern task dispersion (particularly relevant for macro-task platforms and locally-based "apps"). Workers have to establish and maintain a good reputation to continue working on the platform, but the criteria used to determine their rating are not always made available and are difficult to contest. In addition, reputation systems create a lock-in effect for workers given the high costs, both in terms of time and in unpaid qualifications and jobs that are done to establish one's reputation, further undermining the workers' bargaining position vis-à-vis the platform. ${ }^{21}$

Any change to the current conditions of crowd-working platforms will not occur on its own. It requires governments to step in and regulate. The main difficulty that faces government regulation is that the platforms are global. While a platform may be operating from California or Germany, it has clients and workers spread throughout the world. The 2017 ILO survey revealed workers

20 Ajay Agrawal et al., Digitization and the Contract Labor Market: A Research Agenda, NBER Working Paper No. 19525 (2013).

21 Sangeet Paul Choudary, The Architecture of Digital Labour Platforms: Policy Recommendations on Platform Design for Worker Well-Being, ILO Future of Work Working Paper Series (2018). 
located in 75 countries. $^{22}$ Given that a worker is covered by the labour laws of his or her place of residence, this would mean applying and enforcing laws of a vast number of countries. Applying local labour laws from scores of jurisdictions complicates the application of the law, as well as creates differences in standards among workers despite performing the same work, perpetuating labour arbitrage. The other more politically difficult and thus unlikely option would be to institute an international governance system for crowd work that sets and requires platforms (and their clients) to abide by universal minimum standards, as is done with the Maritime Labour Convention, 2006 (MLC, 2006). Though crowd workers do not work in foreign countries as in seafaring, the workforce is international and the platforms and clients, in many cases, reside in foreign countries. Unlike seafaring, however, crowd work is invisible, and the denial of entry into ports that is critical for the effective enforcement of MLC, 2006, is not evident with crowd work. Moreover, deciding on appropriate minimum standards would be difficult, particularly with respect to pay, though such a system could facilitate guidance on occupational safety and health for the psychologically damaging tasks of content moderation (the removal of pornography or violent images before they are uploaded on social media accounts), and could facilitate the creation of contributory social security accounts for the workers.

Nevertheless, the data and the tracking inherent in digital labour platforms do provide important means for monitoring working conditions, once such standards - whether local or international - are established. These data would need to be made available to the regulatory authority, much like enterprise activities can be monitored by labour inspectors. Moreover, if workers are tracked through keystrokes and screen shots, then it seems that they should be given access to this information on their performance, should they need to contest it. Workers should also have access to their work activities and histories in order to prove their employment, should they choose to pursue other professional activities. If given access to their work data, workers would be in a position to turn over the data to a union, which could then use this information in negotiations with platforms. ${ }^{23}$

Regardless of the prevailing laws, if crowd workers are recognized as part of an employment relationship or if other forms of labour protection are extended to crowd workers, the workers could continue to be compensated at piece-rates and the piece-rates could be set up to comply with the established

\footnotetext{
22 Given that the ILO only surveyed English-speaking platforms, this already extensive global representation is understated. 
minimum wages. Technology would facilitate setting this rate, which could be based on average completion time for a task. Technology could also facilitate the monitoring of working hours to ensure that the workers receive paid breaks (as required by many laws governing piece-work). ${ }^{24}$ Having to comply with minimum standards on wages and working hours would put pressure on the employer to ensure that the work is organized in advance and limit the amount of downtime. Time spent looking for work, reading reviews about the requesters to ensure they are fair and honest and taking unpaid qualification tests would thus be eliminated. The productivity gains for workers would be significant. Other aspects of the work would have to be reorganized. For example, a general rule in establishing effective piece-rate systems is to hire fewer employees to ensure that there is sufficient work..$^{25}$ Moreover, an important part of ensuring quality in piece-work is noting the precise reasons for making a rejection as well as establishing a quality control system with a validated scoring system, so that workers can learn from their mistakes. Regulating crowd work would likely force some restructuring in the organization of the work, which would not only be beneficial to the workers, but to the clients and platforms as well.

Conclusion

Micro-task crowd work shares many similarities with industrial home work. It is invisible work broken up into small tasks and dispersed to multiple workers for piece-rate pay. There is a middleman who disperses the work - in this case, a platform - and who takes a fee for this service. The workers are isolated with little contact with other workers and no bargaining power. There is also uncertainty as to whether the worker is an independent contractor or if the person should be classified as an employee, subject to the same labour protection as other workers in an employment relationship. Many women take up this work because of the lack of possibility or constraints on working outside the home, and because home work, digital and traditional, provides a way of combining paid work with domestic responsibilities.

24 See Kamala Sankaran, "Piece-Rated Minimum Wages" (unpublished manuscript), for a discussion of piece-rate legislation in different countries of the world. Many countries issue guidelines on how to calculate piece- rates and how to factor in rest-times.

25 Gregorio Billikopf, Labor Management in Agriculture: Cultivating Personnel Productivity (California, 2003). 
But despite the many similarities between industrial home work and crowd work, the data-centred focus of the latter creates the potential for its effective regulation. However, a first step in improving working conditions would be to establish the standards - whether it should be subject to local laws of the worker's place of residence, or whether a universal standard is needed, given its global nature. Crowd work is emblematic of the challenges inherent in an ever-more globalized and technologically driven world of work. More effort is needed to understand how technology can be used to more effectively regulate and improve working conditions. 